\title{
Treatment prescribing patterns in a cohort of patients with juvenile idiopathic arthritis (JIA). Data from the childhood arthritis prospective study (CAPS)
}

\author{
Rebecca Davies ${ }^{1}$, Roberto Carrasco ${ }^{1}$, Helen E Foster ${ }^{2}$, Eileen Baildam³ ${ }^{3}$ Alice Chieng ${ }^{4}$, Joyce E Davidson ${ }^{5}$, \\ Yiannakis loannou', Lucy Wedderburn? ${ }^{7}$, Wendy Thomson ${ }^{1}$, Kimme Hyrich", \\ Childhood Arthritis Prospective Study (CAPS)
}

From 21st European Pediatric Rheumatology (PReS) Congress

Belgrade, Serbia. 17-21 September 2014

\section{Introduction}

Juvenile idiopathic arthritis (JIA) is a heterogenous disease, classified according to the International League of Associations for Rheumatology (ILAR). Initial treatment is based largely on disease severity; intra-articular injections for oligoarthritis, methotrexate (MTX) for polyarthritis and systemic presentations. The recent licensing of biologic therapies for use in JIA has revolutionised treatment of the disease. It is not currently known what proportion of children who present with polyarthritis will require biologic therapy. Although not studied formally, it is recognised a proportion of children with oligoarthritis will also require systemic therapy to control symptoms.

\section{Objectives}

To describe prescribing patterns in JIA over the first 3 years on presentation to rheumatology.

\section{Methods}

Children with at least 3 years of follow-up within the Childhood Arthritis Prospective Study (CAPS), a prospective observational inception study of inflammatory arthritis, were included.

For analysis, children were placed into one of 4 groups based on physician-assigned ILAR category and number of active joints at first presentation (baseline): oligoarthritis, polyarthritis, systemic (sJIA) and enthesitis-related arthritis

'University of Manchester, Manchester,UK

Full list of author information is available at the end of the article
(ERA). All treatment exposures were categorised into NSAID, intra-articular steroids, disease modifying antirheumatic drug (DMARD) including MTX and sulphasalazine (SSZ) and biologics including adalimumab (ADA), etanercept (ETN), infliximab (INF), and tocilizumab (TCZ).

\section{Results}

790 children were included originally (406 oligoarthritis, 221 polyarthritis, 42 sJIA and 43 ERA). Of these, 78 had missing ILAR and were excluded, leaving 712 children. Over a 3 year period, almost $100 \%$ of children with polyarticular presentation and $50 \%$ with oligoarthritis went on to receive a DMARD. $44 \%$ with polyarthritis and $17 \%$ with oligoarticular presentation also received a biologic (Table). The most recent ILAR category among children with oligoarticular onset who received a biologic comprised $39 \%$ extended, $19 \%$ polyarthritis, $4 \%$ ERA, $11 \%$ other subtypes; $27 \%$ had persistent oligoarthritis. All sJIA patients were treated with DMARDs with $36 \%$ having biologics . 63\% of ERA patients receive a DMARD with $26 \%$ going on to receive a biologic. Table 1 .

\section{Conclusion}

Over a three year period almost all patients with polyarthritis received treatment with MTX and almost 50\% also received a biologic therapy. A high proportion of children presenting with oligoarthritis also went on to receive DMARDs and biologics, many children for persistent oligoarthritis. This is despite the lack of clinical trial evidence 
Table 1

\begin{tabular}{llll}
\hline Arthritis pattern at presentation & $\mathbf{N}$ & Ever had a DMARD, $\mathbf{n}(\%)$ & Ever had a biologic, $\mathbf{n}(\%)$ \\
\hline Oligoarthritis & 406 & $204(50)$ & $70(17)$ \\
\hline Polyarthritis & 221 & $217(98)$ & $98(44)$ \\
\hline Systemic arthritis & 42 & $42(100)$ & $15(36)$ \\
\hline Enthesitis-related arthritis & 43 & $27(63)$ & $11(26)$ \\
\hline
\end{tabular}

for effectiveness in this subtype. Further studies on the efficacy/effectiveness in this subtype should be undertaken to ensure appropriate use of advanced therapies in this population.

\section{Disclosure of interest}

None declared.

\section{Authors' details}

'University of Manchester, Manchester,UK. ${ }^{2}$ Newcastle Hospitals NHS Trust, Newcastle, UK. ${ }^{3}$ Alder Hey Children's NHS Foundation Trust, Liverpool, UK. ${ }^{4}$ Royal Manchester Children's Hospital, Manchester, UK. ${ }^{5}$ Greater Glasgow and Clyde Health Board and Royal Hospital for Sick Children, Glasgow, UK. ${ }^{6}$ Department of Medicine, University College London, London, UK. ${ }^{7}$ Institute of Child Health, Rheumatology Unit, University College London, London, UK.

Published: 17 September 2014

doi:10.1186/1546-0096-12-S1-P23

Cite this article as: Davies et al:: Treatment prescribing patterns in a cohort of patients with juvenile idiopathic arthritis (JIA). Data from the childhood arthritis prospective study (CAPS). Pediatric Rheumatology 2014 12(Suppl 1):P23.

Submit your next manuscript to BioMed Central and take full advantage of:

- Convenient online submission

- Thorough peer review

- No space constraints or color figure charges

- Immediate publication on acceptance

- Inclusion in PubMed, CAS, Scopus and Google Scholar

- Research which is freely available for redistribution

Submit your manuscript at www.biomedcentral.com/submit 